\title{
Prediction of impacts on liver enzymes from the exposure of low-dose medical radiations through artificial intelligence algorithms
}

\author{
Saman Shahid ${ }^{1 *} \oplus$, Khalid Masood² ${ }^{\circledR}$, Abdul Waheed Khan² ${ }^{\circ}$
}

\section{SUMMARY}

OBJECTIVES: This study aimed to develop artificial intelligence and machine learning-based models to predict alterations in liver enzymes from the exposure of low annual average effective doses in radiology and nuclear medicine personnel of Institute of Nuclear Medicine and Oncology Hospital.

METHODS: Ninety workers from the Radiology and Nuclear Medicine departments were included. A high-capacity thermoluminescent was used for annual average effective radiation dose measurements. The liver function tests were conducted for all subjects and controls. Three supervised learning models (multilayer precentron; logistic regression; and random forest) were applied and crossvalidated to predict any alteration in liver enzymes. The t-test was applied to see if subjects and controls were significantly different in liver function tests.

RESULTS: The annual average effective doses were in the range of $0.07-1.15 \mathrm{mSv}$. Alanine transaminase was $50 \%$ high and aspartate transaminase was $20 \%$ high in radiation workers. There existed a significant difference $(p=0.0008)$ in Alanine-aminotransferase between radiation-exposed and radiation-unexposed workers. Random forest model achieved 90-96.6\% accuracies in Alanineaminotransferase and Aspartate-aminotransferase predictions. The second best classifier model was the Multilayer perceptron (65.5-80\% accuracies).

CONCLUSION: As there is a need of regular monitoring of hepatic function in radiation-exposed people, our artificial intelligence-based predicting model random forest is proved accurate in prediagnosing alterations in liver enzymes.

KEYWORDS: Aspartate aminotransferase. Alkaline phosphatase. Bilirubin. Alanine aminotransferase. Radiation dosages. Artificial intelligence. Machine learning.

\section{INTRODUCTION}

Ionizing radiation (IR) is a cancer-causing agent that can alter several biological effects via oxidative stress ${ }^{1-4}$. Oxidative stress in the body can develop a liver injury, which can lead to liver diseases $^{5}$. The liver is a radiosensitive organ ${ }^{6}$, and there is a need that the hepatic function should be monitored in medical radiation-exposed personnel. The current study was conducted to examine the hepatic function in medical radiation workers who are exposed to low doses of medical radiation from the Radiology and Nuclear Medicine departments of Institute of Nuclear Medicine and Oncology (INMOL) Hospital, Pakistan during 2014-2020. For comparisons, radiation-unexposed workers $(n=30)$ of the same institute as controls were also included. The selection of a powerful predictive bio-computational tool

\footnotetext{
'National University of Computer and Emerging Sciences, Foundation for the Advancement of Science and Technology, Department of Sciences \& Humanities - Lahore, Pakistan.

${ }^{2}$ Institute of Nuclear Medicine and Oncology Lahore, Department of Medical Physics - Lahore, Pakistan.

*Correspondence: drshahidsaman@gmail.com

Conflicts of interest: the authors declare there are no conflicts of interest. Funding: none.

Received on October 15, 2020. Accepted on November 16, 2020.
} 
is always a challenge. This study was focused to develop artificial intelligence (AI)-based models to predict alterations in liver enzymes with the following cofactors: age, gender, and exposure to radiation doses. Therefore, three supervised learning models (multilayer precentron, MLP; logistic regression, LR; and random forest, RF) were trained, applied to data, and cross-validated on the samples $(\mathrm{n}=90)$ of radiation-exposed medical workers. We further compared the accuracies and errors of these models and suggested the best. There is an extensive use of X-ray machines, computed tomography (CT), magnetic resonance imaging (MRI), positron emission tomography (PET), intensity-modulated radiotherapy (IMRT), cardiac catheterization, fluoroscopic interventions, intensity-modulated proton therapy (IMPT), conformal therapy (CRT), three-dimensional conformal radiation therapy (3D-CRT), etc. in hospitals for the diagnosis and the treatment of various diseases and cancers. The radiotherapy units and diagnostic instruments are handled by the technicians and physicians, which include a linear particle accelerator (LINAC), the cobalt-60 teletherapy units, brachytherapy units, gamma cameras, mammography units, etc. The Nuclear Medicine department workers handle various radionuclides, such as Tc-99m, F-18, I-131, TI-201, and P-32. Occupational radiation workers, especially from medical procedures and equipment are being chronically exposed to low doses of IRs ${ }^{7-10}$. Low-dose radiation-induced (few $\mathrm{mSv}$ ) late health effects, including cancers, are evident from various studies ${ }^{11-13}$. The liver function test (LFT) has been found effective in diagnosing the elevation or alteration in radiation-induced liver damages ${ }^{14}$. We considered the following liver enzymes to assess: aspartate-aminotransferase (AST), alanine-aminotransferase (ALT), alkaline-phosphatase (ALP), and bilirubin for both radiation-exposed workers and controls (radiation-unexposed workers). A study had reported that a low-dose gamma radiation can impact liver function ${ }^{15}$. Irradiation of the body can lead to a protein oxidation, which can cause DNA damage. Irradiation of a liver can initiate the oxidation of liver enzymes ${ }^{16}$. To diagnose a potential problem in the liver, the ALT and AST are more important from LFT. Their high levels are the indication of specific problems in the liver ${ }^{17}$. The health-risk assessments induced from the exposure to IR were prompted from the calculation and observations from the studies of atomic bomb survivors of Japan. These observations are reported by Nuclear Regulatory Commission, International Commission on Radiological Protection (ICRP), and United Nations Scientific Committee on the Effects of Atomic Radiation (UNSCEAR). The documents of the Radiation Protection Division of the Health Protection Agency are also available as the guidelines to assess the risk of chronic low doses for workers exposed to radiation. It was reported that out of 28 cancers, including liver cancer, the estimated excess relative risk per $\mathrm{Sv}$ was significant ${ }^{4}$.
It has been observed that liver enzymes can be influenced from the exposure of X-rays. The BEIR-V Committee of National Research Council has mentioned that a long-term exposure to radiation can induce a liver cancer ${ }^{18}$. It is known that there was a liver cancer-related mortality risk existed from the exposure of plutonium in Mayak nuclear facility workers ${ }^{19-21}$. Although the liver irradiation risks are reported in patients who were treated with radiotherapies, these risks are not much evaluated in those personnel who are involved in treatments, such as single photon emission computed tomography (SPECT), CT, and 3D-CRT. The radiation-induced liver disease (RILD) has been reported in patients with intrahepatic cancer who were exposed to the radiation dose of 45-84 Gy ${ }^{22}$. Cao et al. (2008) $)^{22}$ mentioned that considerable variations are reported on the sensitivity of the liver in radiation treatment, which can be measured by liver perfusion during the treatment of dynamic contrast-enhanced CT (DCE-CT) scanning.

$\mathrm{AI}$ and machine learning $(\mathrm{ML})$ are extensively being in use to build models and make predictions for useful decisions and outcomes in clinical medicine. The real-time problems can be approximated and solved analytically with such models $s^{23,24}$. ML is considered a method of AI, in which the system learns the given patterns from the data and then with the learning and training functions, the model build-up ${ }^{25}$. Artificial neural networks (ANNs) mimicked the neural networks of human brain. AI and ML can help decide the diagnosis, treatment choices, postprocessing and other calculations through different functions and algorithms ${ }^{25}$. An MLP is a generic ANN model called feed-forward network, which can be adapted to training via learning algorithms. ANNs are the learning methods, which can provide a robust tool to solve real- and discrete-valued functions. ANNs are the interconnected units (neurons), which take real values for the inputs to produce an output ${ }^{26}$. ML algorithms can be used in predictive quantitative models from clinical symptoms and risks, which might be useful in diagnosing earliest risks involved and afterwards, in the selection of the treatment. ML models are characterized by making a few preassumptions, learning mechanisms, and then mine the structured knowledge from the data provided. There are supervised learning methods, such as neural network $(\mathrm{NN})$ algorithms and support vector machines (SVM). There are unsupervised learning methods for clustering and other statistical configurations. For modeling, there should be some available features vs. target variables ${ }^{26,27}$. MLP is a "finite acyclic graph composed of nodes with neurons in logistic activation." The network consists of the input neurons and output neurons in layers. The number of output neurons depends on the target value of each training pattern $^{26,28}$. The MLP algorithms support regression, classification, and prediction problems. ANN-based MLP is a biological 
model mimicking the neurons of the brain, which are formulated into a specific function ${ }^{29}$. The basic random forest (RF) algorithm ${ }^{30-32}$ is a nonparametric general purpose ensemble $\mathrm{ML}$ algorithm ${ }^{26,33}$. An ML-based logistic regression (LR) is a simple, rapid tool, which is effective in solving many problems through training, learning, and achieving specific coefficients ${ }^{26,29}$.

\section{METHODS}

\section{Study design and setting}

A cross-sectional study was conducted in the year 2020 to examine the hepatic function in radiation-exposed medical workers with low dose in two departments (i.e., Radiology [RDG] and Nuclear Medicine [NMD] of INMOL Hospital, Pakistan).

\section{Sample size and data collection}

The low-dose radiation-exposed workers were included as volunteers through informed consents. The average service time for all the included ( $\mathrm{n}=90)$ INMOL radiation-exposed workers was consecutive 5 years (2014-2020). The radiation-unexposed workers $(n=30)$ as controls were also included, who were age-matched and with the same socio-economic background. The control group individuals were also from the same institute. They were scientists, nurses, ward attendants, supervisors, accounts officers, medical assistants, security guards, engineers, technicians, among others. The background/clinical data were collected from all subjects.

\section{Measurement of annual average effective dose in millisieverts}

Thermoluminescent (TLD) dosimeter reader was used to assess the whole-body AAEDs in $\mathrm{mSv}$. The radiation doses in the Radiology and Nuclear Medicine departments were measured by Radiation Dosimetry Laboratory (RDL) ${ }^{35-36}$. The RDL, Pakistan Nuclear Regularity Authority (PNRA) uses a software RaDLab to calculate, assess, and keep record of the TLD received doses, according to the guidelines of ICRP ${ }^{37}$. Few people of the nuclear medicine department were also working with radiopharmaceuticals (Tc-99m and I-131) in Hot and Synthesizer Laboratories.

\section{Blood sampling and background information}

Blood samples were collected from the volunteers $(n=120)$ with informed consents from RDG and NMD radiation-exposed personnel and other unexposed employees of the INMOL hospital. The general background information was recorded on a proforma from each participant.

\section{Liver function test}

The LFTs were conducted for radiation-exposed $(n=90)$ and radiation-unexposed workers $(\mathrm{n}=30)$ in the biochemistry lab of the INMOL hospital. AST in U/L, ALT in U/L, alkaline phosphatase (AP) in $\mathrm{U} / \mathrm{L}$, and bilirubin in $\mathrm{mg} / \mathrm{dl}$ were recorded. The following normal ranges were considered: AP, 115-539 (U/L); ALT, up to 40 (U/L); AST, up to 35 (U/L); and bilirubin, $0.3-1.2(\mathrm{mg} / \mathrm{dL})$.

\section{ARTIFICIAL INTELLEGENCE MODELS}

This study was focused to develop AI-based models to predict alterations in liver enzymes with the following cofactors: age, gender, and exposure to radiation doses (i.e., AAED in $\mathrm{mSv}$ ). For this purpose, three supervised learning models (MLP, LR, and RF) were trained, applied to data, and cross-validated (fivefold) on the samples $(\mathrm{n}=90)$ of radiation-exposed medical workers. All the model buildings were done in Waikato Environment for Knowledge Analysis (WEKA ver. 3.8.3) developed by The University of Waikato Hamilton, New Zealand. Figure 1 shows the flow diagram for the model processing. These models were compared for their accuracies (i.e., kappa statistics, correctly classified instances, TP rate, FP rate, precision, recall, $F$-measure, Matthews correlation coefficient (MCC), receiver operating characteristic ( $\mathrm{ROC}$ ) area, and precision-recall curve (PRC) area and errors (absolute error, root mean squared error, relative absolute error, and root relative squared error). The kappa statistics is a mean to evaluate the prediction performance of the classifiers. Two classes of liver enzymes (ALT and AST) were made according to 'above-therange normal values' in each. Class A in ALT consisted of the values greater than $40 \mathrm{U} / \mathrm{L}$, whereas class $\mathrm{B}$ consisted of the values lesser than B. Similarly, class A in AST consisted of the values greater than $35 \mathrm{U} / \mathrm{L}$, whereas class $B$ consisted of the values lesser than $\mathrm{B}$.

\section{Artificial neural network based multilayer precentron}

An MLP is a function for classification, which includes a back-propagation algorithm. This classifier can be optimized during learning and training phases with certain numbers of epochs. Usually, a Sigmoid function is included in the network of MLP. This model gives the following options for model building: seed, momentum, hidden layers, learning rates, momentum, epochs, batch sizes, training times, etc. The seed is used to initialize the generation of random numbers. The momentum is applied to the weight updates. The hidden layers are used to add where specifically required ${ }^{34}$. 


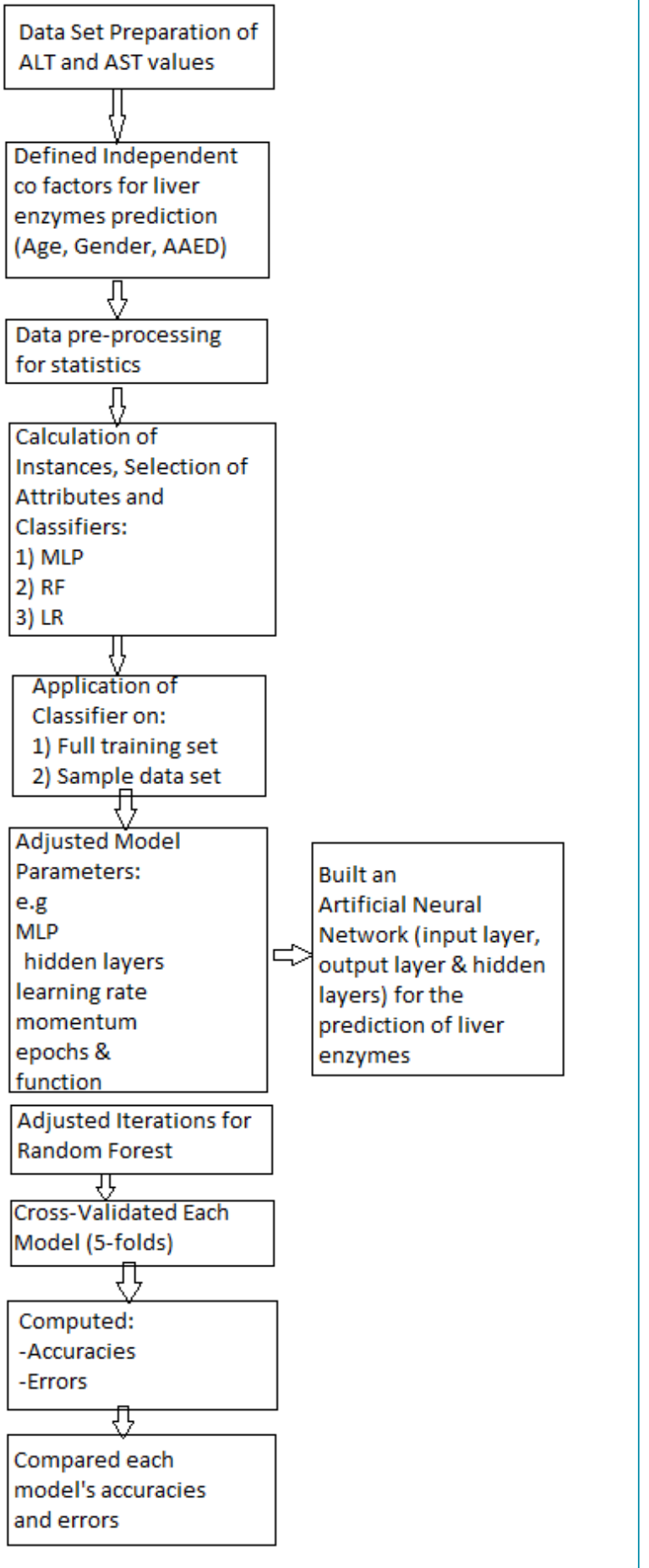

Figure 1. Flow diagram showing all process steps of the models.

\section{Logistic regression}

Logistic is a classifier function used for constructing a multinomial logistic regression (LR) model with a ridge estimator ${ }^{73}$. We used a modified LR from the original to handle the weights of the instances ${ }^{72}$. It gives the option of changing batch size, debug, ridge (in the log-likelihood), maximum number of iterations, or using conjugate gradient descent instead of BroydenFletcher-Goldfarb-Shanno (BFGS) algorithm ${ }^{34}$.

\section{Machine Learning-based random forest}

A RF is a classifier tree for constructing a forest of random trees $^{30}$. It gives the options to change in seed, the number of execution slots to construct the ensemble, bag-size percentage, batch sizes, number of iterations, debug, maximum depth, number of randomly chosen attributes, etc.

\section{Statistical analyses}

The statistical calculations and analyses were done in SPSS version 25. A $t$-test (unpaired) was applied to the mean values of the following: AST (U/L), ALT (U/L), AP (U/L) and bilirubin $(\mathrm{mg} / \mathrm{dl})$ to discover a difference of significance $($ at $\mathrm{p}<0.05)$ between radiation-exposed and radiation-unexposed workers. A $p$-value $<0.050$ was considered significant.

\section{RESULTS}

\section{Background information and annual average effective dose assessment}

Out of 90 medical workers exposed to radiation, 78 (86.7\%) of them were male and $12(13.3 \%)$ were female. The mean age of the radiation-exposed workers was $42.7 \pm 12.08$ years with a range $21-59$ years. There were 19 males $(63.3 \%)$ and $11(36.7 \%)$ females who were radiation-unexposed workers. The mean age of unexposed workers was $44.46 \pm 10.43$ years with a range $27-58$ years. All participants were not found with any hepatic disease during their lifetime.

The mean value of AAED was $0.2550 \pm 0.27516(\mathrm{mSv})$. The personnel of RDG and NMD were exposed to low AAEDs (whole body) in the range of 0.07-1.15 mSv during 2014-2019, which is well below $(<20 \mathrm{mSv})$ the limit implied by UNCEAR.

\section{Mean values of liver function test parameters}

The AP was normal in both radiation-exposed and radiation-unexposed personnel. There were high values reported in ALT and AST enzymes with a mean value of $61.6 \mathrm{U} / \mathrm{L}(\mathrm{n}=45 ; 50 \%)$ and $38.83(\mathrm{n}=18 ; 20 \%)$, respectively, in radiation-exposed workers. There were also high values reported in ALT and AST enzymes with a mean value of $51 \mathrm{U} / \mathrm{L}(\mathrm{n}=5 ; 16.7 \%)$ and $45.8(\mathrm{n}=516.7 \%)$, respectively, in radiation-unexposed workers. Low values in bilirubin were reported in $6(6.7 \%)($ mean $=0.23 \mathrm{mg} / \mathrm{dL})$ radiation-exposed workers and in $3(10 \%)($ mean $=0.27 \mathrm{mg} / \mathrm{dL})$ radiation-unexposed workers. The details are given in Table 1. 


\section{Comparison of classifier models}

The AI-based prediction classifier models were developed to anticipate the alteration in the liver enzymes, ALT and AST, with three cofactors, i.e., age, gender of the radiation-exposed worker, and AAED in the range of $0.07-1.15 \mathrm{mSv}$, using MLP, LR, and RF on cross-validation (fivefold) over 90 samples. Tables 2 and 3 describe the detailed comparisons between these three models along with the their characteristic features.

Table 1. Mean, Min and Max. values of Liver Function Test parameters.

\begin{tabular}{|c|c|c|c|c|}
\hline LFT parameter & Mean \pm SD & Min/Max & High/Low Values (mean) & Normal Range \\
\hline \multicolumn{5}{|l|}{ Radiation Exposed Personnel $(n=90)$} \\
\hline Alkaline Phosphatase (AP) & $222.1667 \pm 42.62701$ & $157.00 / 320.00$ & None & $115-359(\mathrm{U} / \mathrm{L})$ \\
\hline Alanine Transaminase (ALT \%) & $44.8000 \pm 22.02460$ & $18.00 / 102.00$ & High $61.6(n=45 ; 50)$ & Up to $40(\mathrm{U} / \mathrm{L})$ \\
\hline Aspartate Transaminase (AST \%) & $28.9000 \pm 6.48256$ & $16.00 / 43.00$ & High $38.83(n=18 ; 20)$ & Up to 35 (U/L) \\
\hline Bilirubin (\%) & $0.5717 \pm 0.30208$ & $0.22 / 1.80$ & Low $0.23(n=6 ; 6.7)$ & $0.3-1.2(\mathrm{mg} / \mathrm{dL})$ \\
\hline \multicolumn{5}{|l|}{ Radiation Unexposed Personnel $(n=30)$} \\
\hline Alkaline Phosphatase (AP) & $232.2667 \pm 51.54906$ & $150.00 / 348.00$ & None & 115-359 (U/L) \\
\hline Alanine Transaminase (ALT \%) & $30.1667 \pm 12.86825$ & $14.00 / 80.00$ & High $51(n=5 ; 16.7)$ & Up to $40(\mathrm{U} / \mathrm{L})$ \\
\hline Aspartate Transaminase (AST \%) & $28.7333 \pm 10.17412$ & $15.00 / 60.00$ & High $45.8(n=5 ; 16.7)$ & Up to 35 (U/L) \\
\hline Bilirubin (\%) & $0.5367 \pm 0.18907$ & $0.26 / 0.98$ & Low $0.27(n=3 ; 10)$ & $0.3-1.2(\mathrm{mg} / \mathrm{dL})$ \\
\hline
\end{tabular}

Table 2. Comparisons of Al Models (on Five-Fold Cross-Validation) for the Prediction of Alterations in Liver Enzymes (ALT/ AST) in Medical Radiation-Exposed Personnel.

\begin{tabular}{|c|c|c|c|c|c|}
\hline Hidden Layers: 1 (nc & $\begin{array}{r}\text { Mode } \\
\mathrm{S}=2) ; \text { Learning } \mathrm{R}\end{array}$ & $\begin{array}{l}\text { : Multilayer Perce } \\
\text { ate: 0.4; Momentu }\end{array}$ & $\begin{array}{l}\text { ptron (MLP) Clas } \\
\text { m: 0.3; Epochs: }\end{array}$ & $\begin{array}{l}\text { ifier } \\
\text { 0; Batch Size=10 }\end{array}$ & unction: Sigmoi \\
\hline $\begin{array}{l}\text { Correctly Classified } \\
\text { Instances (\%) }\end{array}$ & Kappa Statistics & $\begin{array}{c}\text { Mean Absolute } \\
\text { Error }\end{array}$ & $\begin{array}{l}\text { Root Mean } \\
\text { Squared Error }\end{array}$ & $\begin{array}{c}\text { Relative } \\
\text { Absolute Error } \\
(\%)\end{array}$ & $\begin{array}{c}\text { Root Relative } \\
\text { Squared Error } \\
(\%)\end{array}$ \\
\hline ALT & & & & & \\
\hline 65.5556 & 0.3192 & 0.393 & 0.4455 & 78.8807 & 89.2278 \\
\hline AST & & & & & \\
\hline 80 & 0 & 0.2847 & 0.3829 & 87.5395 & 95.5839 \\
\hline & & $\begin{array}{l}\text { Rel: Logistic Regre } \\
\text { Ridge Paramet }\end{array}$ & $\begin{array}{l}\text { ssion (LR) Classi } \\
\text { er of } 1.0 \mathrm{E}-8\end{array}$ & & \\
\hline ALT & & & & & \\
\hline 48.8889 & -0.036 & 0.4998 & 0.5149 & 100.3204 & 103.1264 \\
\hline AST & & & & & \\
\hline 78.8889 & 0.1441 & 0.2873 & 0.3821 & 88.3471 & 95.3939 \\
\hline & Bagging & $\begin{array}{l}\text { odel: Random T } \\
\text { th } 100 \text { iteration }\end{array}$ & $\begin{array}{l}\text { ee (RF) Classifiel } \\
\text { and base learn€ }\end{array}$ & ; Seed=1 & \\
\hline ALT & & & & & \\
\hline 90 & 0.7982 & 0.1696 & 0.2526 & 34.0503 & 50.5894 \\
\hline AST & & & & & \\
\hline 96.6667 & 0.898 & 0.0908 & 0.1618 & 27.9296 & 40.3842 \\
\hline
\end{tabular}

ALT: alanine transaminase; AST: aspartate aminotransferase. 


\section{Machine Learning-based Random Forest} According to the results, the best model was the RF, which achieved $90 \%$ and $96.6 \%$ accuracies in ALT and AST predictions, respectively, with the defined cofactors. RF model achieved a reduced number of errors and good kappa statistics (i.e., 79\% and 89\%) (Tables 2 and 3).

\section{Artificial Neural Network-based Multilayer Perception}

The second best classifier model was the MLP with respect to the accuracies and errors for both ALT and AST. The MLP model was tested and trained on different learning rates (LR), momentum, number of hidden layers, epochs, and the hidden layers. The best accuracy was found with one hidden layer of two nodes, $\mathrm{LR}=0.4$, momentum $=0.3$, and epcohs $=500$. Figure $2 \mathrm{~A}$ and $\mathrm{B}$ show the ANN of MLP with and without hidden layers.

\section{Machine Learning-based logistic regression}

This model worked well for AST prediction with 78\% accuracy as compared to $48 \%$ accuracy in predicting ALT. The odds ratios in class A (values more than $40 \mathrm{U} / \mathrm{L}$ ) of the ALT model were as follows: age $=1.0342$; gender: female $=1.3057$; and $\mathrm{AAED}=0.5493$. The odds ratios in class $\mathrm{A}$ (values more than $35 \mathrm{U} / \mathrm{L}$ ) of the AST model were as follows: age=1.0619; gender: female $=0$; and $\mathrm{AAED}=0.1614$.

\section{Comparisons based on t-test}

The $t$-test was applied to see if both groups (radiation-exposed and radiation-unexposed workers) were significantly different from each other in LFT parameters. There existed a significant difference $(\mathrm{p}=0.0008 ; 95 \% \mathrm{CI} \mathrm{t}=3.445 ; \mathrm{df}=118 ; 6.22-23.05)$ in the mean values of ALT between radiation-exposed and radiation-unexposed workers. There existed a nonsignificant difference in the mean values of AP, AST, and bilirubin with the following p-values: $0.2890,0.9169$, and 0.554 , respectively.

\section{DISCUSSION}

Liver is a radiosensitive organ ${ }^{6}$, and the long-term low-dose radiation effects must be regularly monitored in occupational workers. It has been reported that a radiation exposure can induce hepatic toxicity and can increase the risk of hepatic

Table 3. Comparisons of Al models: accuracy details by class.

\begin{tabular}{|c|c|c|c|c|c|c|c|c|}
\hline \multicolumn{9}{|c|}{ Model: Multilayer Perceptron (MLP) Classifier } \\
\hline Class & TP Rate & FP Rate & Precision & Recall & F-Measure & $\mathrm{MCC}$ & ROC Area & PRC Area \\
\hline \multicolumn{9}{|l|}{ ALT } \\
\hline A & 0.762 & 0.438 & 0.604 & 0.762 & 0.674 & 0.329 & 0.696 & 0.694 \\
\hline B & 0.563 & 0.238 & 0.730 & 0.563 & 0.635 & 0.329 & 0.696 & 0.767 \\
\hline \multicolumn{9}{|l|}{ AST } \\
\hline A & 1.000 & 1.000 & 0.800 & 1.000 & 0.889 & - & 0.700 & 0.909 \\
\hline B & 0.000 & 0.000 & - & 0.000 & - & - & 0.700 & 0.366 \\
\hline \multicolumn{9}{|c|}{ Model: Logistic Regression (LR) Classifier } \\
\hline \multicolumn{9}{|l|}{ ALT } \\
\hline A & 0.381 & 0.417 & 0.444 & 0.381 & 0.410 & -0.036 & 0.494 & 0.456 \\
\hline B & 0.583 & 0.619 & 0.519 & 0.583 & 0.549 & -0.036 & 0.494 & 0.549 \\
\hline \multicolumn{9}{|l|}{ AST } \\
\hline A & 0.944 & 0.833 & 0.819 & 0.944 & 0.877 & 0.166 & 0.723 & 0.922 \\
\hline B & 0.167 & 0.056 & 0.429 & 0.167 & 0.240 & 0.166 & 0.723 & 0.355 \\
\hline \multicolumn{9}{|c|}{ Model: Random Forest (RF) Classifier } \\
\hline \multicolumn{9}{|l|}{ ALT } \\
\hline A & 0.857 & 0.063 & 0.923 & 0.857 & 0.889 & 0.800 & 0.976 & 0.974 \\
\hline B & 0.938 & 0.143 & 0.882 & 0.938 & 0.909 & 0.800 & 0.976 & 0.980 \\
\hline \multicolumn{9}{|l|}{ AST } \\
\hline A & 0.972 & 0.056 & 0.986 & 0.972 & 0.979 & 0.898 & 0.997 & 0.999 \\
\hline B & 0.944 & 0.028 & 0.895 & 0.944 & 0.919 & 0.898 & 0.997 & 0.983 \\
\hline
\end{tabular}

TP: true positive; FP: false positive; MCC: Matthews correlation coefficient; ROC: receiver operating characteristic; PRC: precision-recall curve; ALT: alanine transaminase; AST: aspartate aminotransferase. 


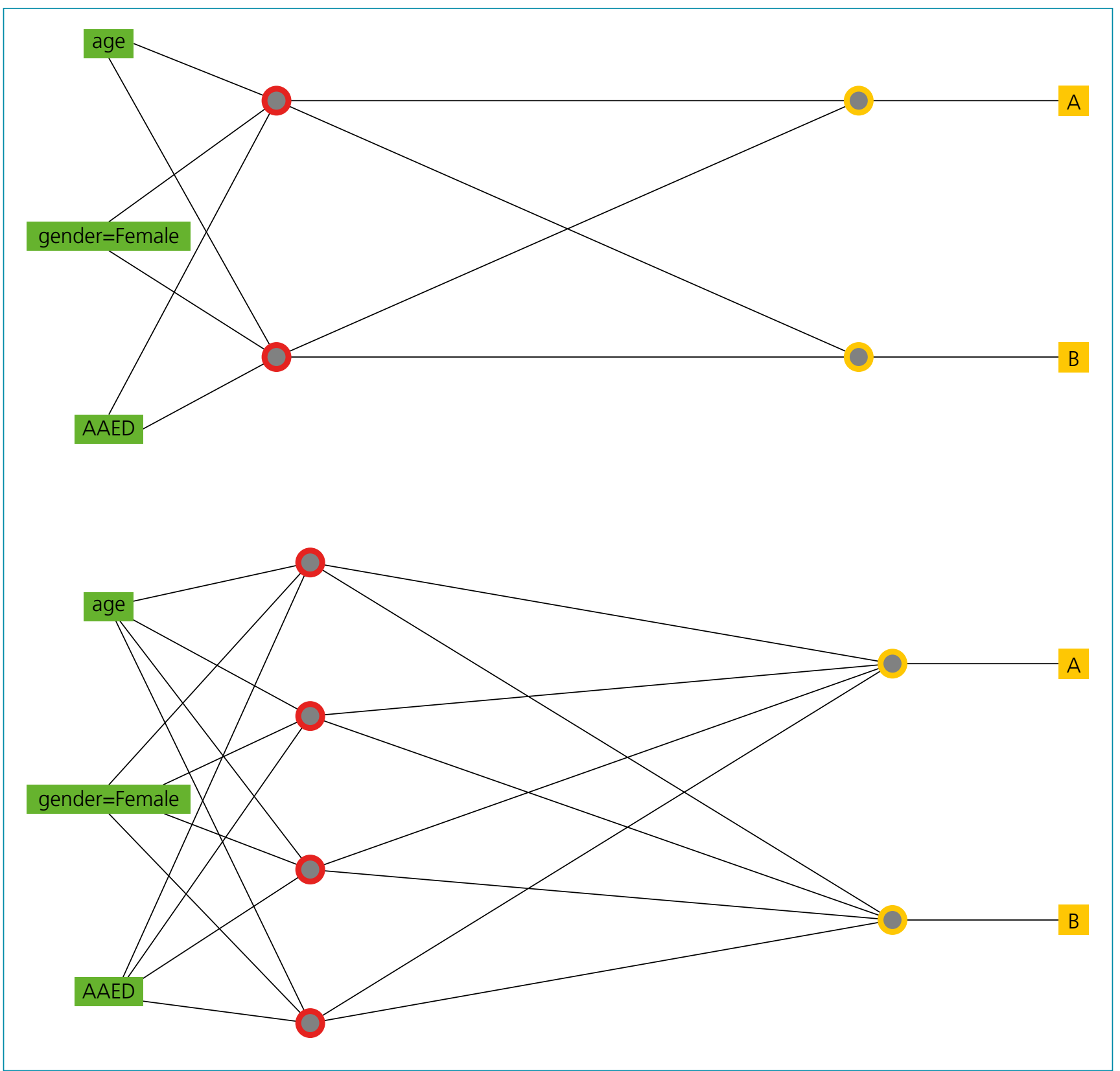

Figure 2. (A) Top: Neural network of liver enzymes with one hidden layer (nodes: 2); (B) bottom: Neural network of liver enzymes with one hidden layer (nodes; 4).

cancers ${ }^{19}$. Liver cancer has been reported ${ }^{12}$ in medical radiation workers who were exposed from low doses. A study reported that the X-ray workers were found with high risks of leukemia, lung, liver, and breast cancers from the chronic exposure of radiations $s^{38}$. The workers of the Mayak nuclear production facility have been diagnosed with high risks of mortality from liver, lung, and bone cancers ${ }^{20-40}$. Similarly, the mortalities were also reported from liver cancer in the workers of the Sellafield nuclear plant in Britain ${ }^{41}$. We figured out a best predicting model from AI and ML-based algorithms for the impact on liver enzymes with the following cofactors: age, gender, and low doses of AAEDs $(\mathrm{mSv})$ in radiology and nuclear medicine workers of the INMOL hospital. Among three supervised learning models (MLP, LR, and RF), the ML-based classifier RF achieved high accuracies (90-96\%) in predicting altered levels of liver enzymes, AST and ALT. The ML-based decision tree models have been used for the detection or diagnosis of the diseases ${ }^{42-46}$. ML tools are now considered more powerful to assist in the decision making for problems in medical science ${ }^{46}$. ML is a branch of AI that has been found best in its 
implications in nonlinear biological systems with complex measurements ${ }^{46}$. The ML-based RFs or the random decision forests are the ensembling learning methods for the classification and regression by building a multitude of decision trees via training. The RF consists of many individual decision trees, with each tree splits on a class prediction, and the class which is most opted, becomes the model's prediction ${ }^{47}$.

According to the study conducted by Boice et al. ${ }^{48}$, the cancer risks were evaluated in the employees of Rocketdyne (Atomic International), who were having an intake of radionuclides. They reported that the lung cancer and other cancers of liver, bone, esophagus, and kidney were not reported from the average dose of the external radiation of $13.5 \mathrm{mSv}$. However, cardiovascular disease, diabetes, the cirrhosis of the liver and other respiratory diseases were reported with significant deficits. Guha and Kavanagh ${ }^{49}$ reported the RILD within 4 months in patients receiving hepatic radiation therapy. They reported higher levels of AP, but normal levels of bilirubin and ammonia through LFT. Lian et al. ${ }^{50}$ assessed the severity and risk factors of liver radiation tolerance in more than 100 primary liver cancer patients who were treated with 3D-CRT. Although, they found that the mean dose of 23 Gy was tolerable for a normal liver, however, they did not asses the hepatic radiation tolerance from the dosimetry calculations. They suggested that the most important risk factor for RILD was related to the liver cirrhosis. Wang et al $(2013)^{51}$ has mentioned that during radiotherapy, the $99 \mathrm{mTc}$-labeled immindodiacetic acid (IDA) SPECT obtained can be employed to assess the hepatic function, which can help to anticipate any post radiotherapy liver function alteration. Therefore, an optimized radiation treatment plan can be decided to avoid RILD in patients ${ }^{51}$. Howe et al. and Azizova \& Muirhead ${ }^{52,53}$ had mentioned that the chronic use of radiation can induce some changes in liver metabolism in many occupational radiation-exposed groups. When a liver receives radiation doses via whole-body exposure, the "upregulation in the genes of main proinflammatory chemokines occurs from the activity of proinflammatory cytokines" 34,55 . "An exposure of radiation induces the oxidative stress and this in turn can impact the liver through increase in concentrations of thiobarbituric acid-reactive substances (TBARS), decrease in superoxide dismutase, glutathione peroxidase activity $^{55,56}$, reduced glutathione concentration (GSH), and hence an activation of the stress-inducible haemoxygenase-1 (HO-1) gene" 57 . It is known that the reduced levels of GSH can lead to the increased stress induced oxidation ${ }^{58}$. The HO- 1 gene has a protective function as anti-inflammation and antioxidant and has a role in the production of bilirubin ${ }^{59,60}$. However, some researchers did not report any change in TBARS levels from the radiation exposure ${ }^{61,62}$. The elevation in hepatocyte growth factor was observed with the exposure of total body irradiation ${ }^{55-63}$. A whole-body irradiation can impact other body organs, including the liver. Nwokocha et al..$^{55}$ conducted a study in which they evaluated the impacts of total-body radiation $(1.27 \mathrm{~Gy} / \mathrm{min}$ for 5 days), which leads to the alterations in liver enzymes in rats. They found that the levels of ALT and AST were significantly increased with the increase in the radiation doses. The decreased serum total protein and albumin levels were also reported from radiation exposures, mentioned by Holten and Christiansen, Moulder et al, and Wheeler and Bernard ${ }^{64-66}$. An increase in cholesterol and lipid levels were also reported from the radiation injury, due to the increased inflammatory actions ${ }^{38,39}$. Nwokocha et al..$^{55}$ reported that with the radiation exposure, the levels of bilirubin varied within the normal range, and the high levels were not significant.

LFT is the first helpful screening to find out any dysfunctioning in the hepatic system ${ }^{69}$. "Overproduction and leakage in blood are the basis of abnormality in AP levels. Leakage from the damaged tissue is a basis of normality in ALT/AST levels. The elevated levels of ALT/AST are used to mark in hepatitis, autoimmune diseases, toxicity, and ischemic conditions. Mild high levels of AST can be an indication of a liver disease; whereas, its moderate levels can be the indication of extrahepatic biliary atresia (EHBA), IHBA (intrahepatic biliary hypoplasia), infiltrating disorders or granulomatous hepatitis. The basis of normality in bilirubin is related to the decreased hepatic clearance. Its mild increased levels can indicate physiological jaundice, inherited hyperbilirubinemia; whereas, its moderate high levels can indicate EHBA, IHBA, drug toxicity, viral hepatitis, or inherited hyperbilirubinemia" ${ }^{69}$. There existed a significant difference $(\mathrm{p}=0.0008)$ in ALT between radiation-exposed and radiation-unexposed workers. None of the radiation-exposed or radiation-unexposed people of INMOL were having an abnormal value of AP. The major change was observed in ALT, which was high in $50 \%$ radiation-exposed workers. The AST was high in $20 \%$ radiation-exposed workers. Only $6.7 \%$ lower levels were found in bilirubin in radiation-exposed workers. "It is known that the extremely high levels of ALT/AST are found in viral hepatitis, drug toxicity induced hepatic necrosis, and circulatory shock. Moderate-high levels of ALT/AST are found in patients with acute/chronic hepatitis, autoimmune hepatitis, drug-induced hepatitis, alcoholic hepatitis, and acute biliary tract obstructions. In chronic liver diseases, the ALT can frequently increase. The mild high levels of ALT/AST are seen in EHBA, fatty liver, liver cirrhosis, nonalcoholic steato hepatitis (NASH), drug toxicity, myositis, Duchenne muscular dystrophy or after strenuous exercises. The lower levels of bilirubin may be reported from the side effects of certain drugs, such as sulphonamides and salicylates" ${ }^{\prime \prime}$. Abnormalities in liver enzymes 
are commonly reported in elderly people ${ }^{70}$. The elevated levels of ALT/AST can be observed in short duration and may not point towards any significant damage to the liver. A chronic intake of antidepressants, pain relief medicines, antibiotics, or muscle relaxants can temporarily raise liver enzymes. BarshishatKupper et al. ${ }^{16}$ reported a hepatic metabolic alteration with the radiations of $8.5 \mathrm{~Gy}$, which also led to the radiation-induced carbonylation of associated liver enzymes. A study had reported that the altered levels of AST, AP, and bilirubin were significantly linked with the radioactivity of thorium in occupational workers ${ }^{71}$. Moreover, high levels of AST, AP, bilirubin, and albumin were significantly associated with the alpha-radiation (50 $\mu \mathrm{Ci})$ emission from the radium industry in female workers ${ }^{72}$.

\section{Recommendations}

There is a need to evaluate the same models on large data. There should be some planning in implementing these models in hospitals for the health and safety of the radiation workers. The practical implications could provide the real testing to solve for the errors and other limitations. More AI and ML-based models can also be tested with more specific cofactors for their robustness and validations. There should also be more consideration of different learning methods and more data for the training samples. Moreover, the developed AI models can be further helpful in diagnosing any intial health abnormality in patients who receive radiotherapies.

\section{Limitations and strengths}

This was a single-center based pilot study and was conducted to test the validity of $\mathrm{AI}$ and $\mathrm{ML}$ predictive models for the prediagnosis of biochemistry alterations. Although, few specific models were successfully validated, there is a need to test more AI models on larger data. The accuracy in the results of the tested models indicates that they can help clinicians to prediagnose any abnormality in the biochemistry of popultation who are being exposed to environmental toxics.

\section{CONCLUSION}

A radiation-induced injury can occur in the medical radiation workers from low doses. Therefore, there is a need to monitor the hepatic function of radiation-exposed people on a regular basis. The RF achieved the highest accuracy in predicting the altered levels of liver enzymes. The application of ML-based models can provide us fast monitoring and assessment of biochemistry to point out an earliest risk in case of any alterations.

\section{AUTHORS" CONTRIBUTIONS}

SS: Conceptualization, Formal Analysis, Writing - Original Draft. KM: Data Curation, Writing - Review \& Editing. AWK: Data Curation, Writing - Review \& Editing.

\section{REFERENCES}

1. Pernot E, Hall J, Baatout S, Benotmane MA, Blanchardon E, Bouffler $S$, et al. lonizing radiation biomarkers for potential use in epidemiological studies. Mutat Res. 2012;751(2):25886. https://doi.org/10.1016/j.mrrev.2012.05.003

2. Karbownik M, Reiter RJ. Antioxidative effects of melatonin in protection against cellular damage caused by ionizing radiation. Proc Soc Exp Biol Med. 2000;225(1):9-22. https:// doi.org/10.1046/j.1525-1373.2000.22502.x

3. Fazel R, Krumholz HM, Wang $Y$, Ross JS, Chen J, Ting HH, et al. Exposure to low-dose ionizing radiation from medical imaging procedures. N Engl J Med. 2009;361(9):849-57. https://doi.org/10.1056/NEJMoa0901249

4. Muirhead CR, O'Hagan JA, Haylock RG, Phillipson MA, Willcock T, Berridge GL, et al. Mortality and cancer incidence following occupational radiation exposure: third analysis of the National Registry for Radiation Workers. Br J Cancer. 2009;100(1):206-12. https://doi.org/10.1038/sj.bjc.6604825

5. Li S, Tan HY, Wang N, Zhang Z, Lao L, Wong CW, et al. The Role of Oxidative Stress and Antioxidants in Liver Diseases. Int J Mol Sci. 2015;16(11):26087-124. https://doi.org/10.3390/ijms161125942

6. Kłuciński P, Mazur B, Kaufman J, Hrycek A, Cieślik P, Martirosian $G$. Assessment of blood serum immunoglobulin and C-reactive protein concentrations in workers of x-ray diagnostics units. Int J Occup Med Environ Health. 2005;18(4):327-30. PMID 16617848

7. Tien HC, Tremblay LN, Rizoli SB, Gelberg J, Spencer F, Caldwell $C$, et al. Radiation exposure from diagnostic imaging in severely injured trauma patients. J Trauma. 2007;62(1):151-6. https:// doi.org/10.1097/TA.0b013e31802d9700

8. Linet MS, Kim KP, Miller DL, Kleinerman RA, Simon SL, Gonzalez AB. Historical review of occupational exposures and cancer risks in medical radiation workers. Radiat Res. 2010;174(6):793-808. https://doi.org/10.1667/RR2014.1

9. Venneri L, Rossi F, Botto N, Andreassi MG, Salcone N, Emad $A$, et al. Cancer risk from professional exposure in staff working in cardiac catheterization laboratory: insights from the National Research Council's Biological Effects of lonizing Radiation VII Report. Am Heart J. 2009;157(1):118-24. https:// doi.org/10.1016/j.ahj.2008.08.009

10. Rashid A, Salman S, Waheed A, Jahanzeb K, Orfi S. Code of Practice for Safe Use of Radiation at PINSTECH. Islamabad: PINSTECH/HPD-101; 2006. [cited on Nov. 21, 2009]. Available from: https://inis.iaea.org/collection/NCLCollectionStore/_ Public/44/019/44019551.pdf 
11. Vrijheid M, Cardis E, Ashmore P, Auvinen A, Bae J, Engels H, et al. Mortality from diseases other than cancer following low doses of ionizing radiation: results from the 15-Country Study of nuclear industry workers. Int J Epidemiol. 2007;36(5):112635. https://doi.org/10.1093/ije/dym138

12. Zielinski J, Garner M, Band P, Krewski D, Shilnikova N, Jiang $\mathrm{H}$, et al. Health outcomes of low-dose ionizing radiation exposure among medical workers: a cohort study of the Canadian national dose registry of radiation workers. Int J Occup Med Environ Health. 2009;22(2):149-56. https://doi. org/10.2478/v10001-009-0010-y

13. Brown KR, Rzucidlo E. Acute and chronic radiation injury. J Vasc Surg. 2011;53(Suppl 1):15S-21S. https://doi.org/10.1016/j. jvs.2010.06.175

14. Nwokocha $C$, Nwokocha M, Mounmbegna P, Orhue J, Onyezuligbo O, Olu-Osifo $E$, et al. Proteins and liver function changes in rats following cumulative total body irradiations. West Indian Med J. 2012;61(8):773-7. PMID: 23757896

15. Bakshi MV, Azimzadeh O, Barjaktarovic Z, Kempf SJ, Merl-Pham J, Hauck SM, et al Total body exposure to low-dose ionizing radiation induces long-term alterations to the liver proteome of neonatally exposed mice. J Proteome Res. 2015;14(1):36673. https://doi.org/10.1021/pr500890n

16. Barshishat-Kupper M, Tipton AJ, McCart EA, McCue J, Mueller GP, Day RM. Effect of ionizing radiation on liver protein oxidation and metabolic function in C57BL/6J mice. Int J Radiat Biol. 2014;90(12):1169-78. https://doi.org/10.3 109/09553002.2014.930536

17. Chang Y, Ryu S, Zhang Y, Son HJ, Kim JY, Cho J, et al. A cohort study of serum bilirubin levels and incident non-alcoholic fatty liver disease in middle aged Korean workers. PLoS One. 2012;7(5):e37241. https://doi.org/10.1371/journal. pone. 0037241

18. Center for Environmental Health Studies. Liver cancer and (including intra-hepatic bile duct) exposure to ionizing radiation. Boston: Center for Environmental Health Studies; 1992. [cited on Dec. 23, 2019]. Available from: https://www2.clarku.edu/ mtafund/prodlib/jsi/Liver_Cancer_and_Exposure_to_lonizing_ Radiation.pdf

19. Ohishi W, Fujiwara S, Cologne JB, Suzuki G, Akahoshi M, Nishi $\mathrm{N}$, et al. Impact of radiation and hepatitis virus infection on risk of hepatocellular carcinoma. Hepatology. 2011;53(4):1237-45. https://doi.org/10.1002/hep.24207

20. Gilbert E, Koshurnikova N, Sokolnikov M, Khokhryakov V, Miller S, Preston D, et al. Liver cancers in Mayak workers. Radiat Res. 2000;154(3):246-52. https://doi.org/10.1667/00337587(2000)154[0246:Icimw]2.0.co;2

21. Tokarskaya ZB, Zhuntova GV, Scott BR, Khokhryakov VF, Belyaeva ZD, Vasilenko EK, et al. Influence of alpha and gamma radiations and non-radiation risk factors on the incidence of malignant liver tumors among Mayak PA workers. Health Phys. 2006;91(4):296-310. https://doi.org/10.1097/01. HP.0000215840.24538.8b

22. Cao Y, Pan C, Balter JM, Platt JF, Francis IR, Knol JA, et al. Liver function after irradiation based on computed tomographic portal vein perfusion imaging. Int J Radiat Oncol Biol Phys. 2008;70(1):154-60. https://doi.org/10.1016/j. ijrobp.2007.05.078

23. Ingle YS, Mokhade A. Use of linear regression in machine learning for ranking. IJSRD. 2013;1(5):1135-40. [cited on Jan. 21, 2020]. Available from: https://www.researchgate.
net/publication/342492990_Use_of_Linear_Regression_in_ Machine_Learning_for_Ranking

24. Freitas N. Linear regression. United Kingdom: University of Oxford; 2015. [cited on Jan. 22, 2020]. Available from: https:// www.cs.ox.ac.uk/people/nando.defreitas/machinelearning/ lecture2.pdf

25. Choi H. Deep learning in nuclear medicine and molecular imaging: current perspectives and future directions. Nucl Med Mol Imaging. 2018;52(2):109-18. https://doi.org/10.1007/ s13139-017-0504-7

26. Mitchell TM. Machine learning. New York: McGraw-hill; 1997. p.414.

27. Bzdok D, Meyer-Lindenberg A. Machine learning for precision psychiatry: opportunities and challenges. Biol Psychiatry Cogn Neurosci Neuroimaging. 2018;3(3):223-30. https:// doi.org/10.1016/j.bpsc.2017.11.007

28. Riedmiller M. Machine learning: generalisation in multilayer perceptrons. Freiburg: University of Freiburg. [cited on Dec. 24, 2019]. Available: http://ml.informatik.uni-freiburg. de/former/_media/teaching/ss10/06_mlp_generalisation. printer.pdf

29. Brownlee J. How to use regression machine learning algorithm in Weka. 2016. San Francisco: Machine Learning Mastery. [cited on Nov. 24, 2019]. Available from: https://machinelearningmastery. com/use-regression-machine-learning-algorithms-weka/

30. Breiman L. Random forests. Machine learning. 2001;45(1):532. https://doi.org/10.1023/A:1010933404324

31. Cutler A, Cutler DR, Stevens JR. Random forests. In: Zhang C, Ma YQ, editors. Ensemble machine learning. New York: Springer; 2012. p.157-75. https://doi.org/10.1007/978-14419-9326-7_5

32. Cutler DR, Edwards Junior TC, Beard KH, Cutler A, Hess KT, Gibson J, et al. Random forests for classification in ecology. Ecology. 2007;88(11):2783-92. https://doi.org/10.1890/070539.1

33. Biau G. Analysis of a random forests model. Journal of Machine Learning Research. 2012;13:1063-95. [cited on Nov. 24, 2019]. Available from: https://jmlr.org/papers/volume13/ biau12a/biau12a.pdf

34. Garner SR. WEKA: The Waikato Environment for Knowledge Analysis. The University of Waikato, Hamilton: University of Waikato; 2018. [cited on Nov. 24, 2019]. Available from: https://www.cs.waikato.ac.nz/ ml/publications/1995/Garner95WEKA.pdf

35. International Commission on Radiological Protection (ICRP). Recommendations of the International Commission on Radiological Protection, ICRP Publication No. 60. New York: Pergamon Press; 1990. [cited on Feb. 03, 2020]. Available from: https://journals.sagepub.com/doi/pdf/10.1177/ANIB_21_1-3

36. The Gazette of Pakistan. PART II, Statutory Notifications (SRO) PAK/904, Government of Pakistan, Pakistan Nuclear Regulatory Authority (PNRA), Published by Authority, Islamabad, 2004. [cited on Mar. 21, 2021]. Available from: https://pnra.org/ upload/legal_basis/PAK904-Amended.pdf

37. Jabeen A, Masood M, Munir M, Ahmed K. Occupational exposure at research reactors, isotope production, and applied health physics in Pakistan during 2003-2007. Nuclear Technology and Radiation Protection. 2010;25(2):138-42. https://doi.org/10.2298/NTRP1002138J 
38. Wang JX, Zhang LA, Li BX, Zhao YC, Wang ZQ, Zhang JY, et al. Cancer incidence and risk estimation among medical $\mathrm{x}$-ray workers in China, 1950-1995. Health Phys. 2002;82(4):45566. https://doi.org/10.1097/00004032-200204000-00004

39. Brown SC, Schonbeck MF, McClure D, Barón AE, Navidi WC, Byers $T$, et al. Lung cancer and internal lung doses among plutonium workers at the Rocky Flats Plant: a case-control study. Am J Epidemiol. 2004 Jul 15;160(2):163-72. https:// doi.org/10.1093/aje/kwh192

40. Sokolnikov ME, Gilbert ES, Preston DL, Ron E, Shilnikova NS, Khokhryakov VV, et al. Lung, liver and bone cancer mortality in Mayak workers. Int J Cancer. 2008;123(4):905-11. https:// doi.org/10.1002/ijc.23581

41. Smith PG, Douglas AJ. Mortality of workers at the Sellafield plant of British Nuclear Fuels. Br Med J (Clin Res Ed). 1986;293(6551):845-54. https://doi.org/10.1136/ bmj.293.6551.845

42. Simes RJ. Treatment selection for cancer patients: application of statistical decision theory to the treatment of advanced ovarian cancer. J Chronic Dis. 1985;38(2):171-86. https:// doi.org/10.1016/0021-9681(85)90090-6

43. Maclin PS, Dempsey J, Brooks J, Rand J. Using neural networks to diagnose cancer. J Med Syst. 1991;15(1):11-9. https://doi. org/10.1007/BF00993877

44. Cicchetti DV. Neural networks and diagnosis in the clinical laboratory: state of the art. Clin Chem. 1992;38(1):9-10. PMID: 1733613

45 McCarthy JF, Marx KA, Hoffman PE, Gee AG, O'Neil P, Ujwal ML, et al. Applications of machine learning and highdimensional visualization in cancer detection, diagnosis, and management. Ann N Y Acad Sci. 2004;1020:239-62. https:// doi.org/10.1196/annals.1310.020

46. Cruz JA, Wishart DS. Applications of machine learning in cancer prediction and prognosis. Cancer Inform. 2007;2:5977. PMID: 19458758

47. Yiu T. Understanding random forest. How the algorithm works and why it is so effective. Medium; 2012. [cited on Feb. 18, 2020]. Available from: https://towardsdatascience. com/understanding-random-forest-58381e0602d2

48. Boice Junior JD, Cohen SS, Mumma MT, Ellis ED, Eckerman $\mathrm{KF}$, Leggett RW, et al. Updated mortality analysis of radiation workers at Rocketdyne (Atomics International), 1948-2008. Radiat Res. 2011;176(2):244-58. https://doi.org/10.1667/ RR2487.1

49. Guha C, Kavanagh BD. Hepatic radiation toxicity: avoidance and amelioration. Semin Radiat Oncol. 2011;21(4):256-63. https://doi.org/10.1016/j.semradonc.2011.05.003

50. Liang SX, Zhu XD, Xu ZY, Zhu J, Zhao JD, Lu HJ, et al. Radiationinduced liver disease in three-dimensional conformal radiation therapy for primary liver carcinoma: the risk factors and hepatic radiation tolerance. Int J Radiat Oncol Biol Phys. 2006;65(2):42634. https://doi.org/10.1016/j.jirobp.2005.12.031

51. Wang $H$, Feng $M$, Frey KA, Ten Haken RK, Lawrence TS, Cao Y. Predictive models for regional hepatic function based on 99mTc-IDA SPECT and local radiation dose for physiologic adaptive radiation therapy. Int J Radiat Oncol Biol Phys. 2013;86(5):1000-6. https://doi.org/10.1016/j. ijrobp.2013.04.007

52. Howe GR, Zablotska LB, Fix JJ, Egel J, Buchanan J. Analysis of the mortality experience amongst U.S. nuclear power industry workers after chronic low-dose exposure to ionizing radiation.
Radiat Res. 2004;162(5):517-26. https://doi.org/10.1667/ rr3258

53. Azizova T, Muirhead C. Epidemiological evidence for circulatory diseases-occupational exposure. Emerging evidence for radiation induced circulatory diseases. Luxemburg: Health Protection Agency; 2008. [cited on Oct. 02, 2019]. Available from: https://ec.europa.eu/energy/sites/default/files/documents/ epidemiological_evidence_for_circulatory_diseases_-occupational_exposure.pdf

54. Moriconi F, Christiansen H, Raddatz D, Dudas J, Hermann RM, Rave-Fränk $M$, et al. Effect of radiation on gene expression of rat liver chemokines: in vivo and in vitro studies. Radiat Res. 2008;169(2):162-9. https://doi.org/10.1667/RR1006.1

55. Nwokocha CR, Nwokocha M, Mounmbegna P, Orhue J, Onyezuligbo $\mathrm{O}$, Olu-Osifo $\mathrm{EH}$, et al. Proteins and liver function changes in rats following cumulative total body irradiations. West Indian Med J. 2012;61(8):773-7. PMID: 23757896

56. Suzuki K, Mori M, Kugawa F, Ishihara H. Whole-body $X$-irradiation induces acute and transient expression of heme oxygenase-1 in rat liver. J Radiat Res. 2002;43(2):205-10. https://doi.org/10.1269/jrr.43.205

57. Andrade E, Cruz I, Andrade V, Piccoli J, González-Gallego J, Barrio J, et al. Evaluation of the potential protective effects of ad libitum black grape juice against liver oxidative damage in whole-body acute X-irradiated rats. Food Chem Toxicol. 2011;49(4):1026-32. https://doi.org/10.1016/j.fct.2011.01.011

58. Dickinson DA, Forman HJ. Cellular glutathione and thiols metabolism. Biochem Pharmacol. 2002;64(5-6):1019-26. https://doi.org/10.1016/s0006-2952(02)01172-3

59. Otterbein LE, Choi AM. Heme oxygenase: colors of defense against cellular stress. Am J Physiol Lung Cell Mol Physiol. 2000;279(6):L1029-37. https://doi.org/10.1152/ ajplung.2000.279.6.L1029.

60. Abraham N, Drummond G, Lutton J, Kappas A. The biological significance and physiological role of heme oxygenase. Cell Physiol Biochem. 1996;6(3):129-68. https://doi. org/10.1159/000154819

61. Torres-Duran PV, Ferreira-Hermosillo A, Juarez-Oropeza MA, Elias-Viñas D, Verdugo-Diaz L. Effects of whole body exposure to extremely low frequency electromagnetic fields (ELF-EMF) on serum and liver lipid levels, in the rat. Lipids Health Dis. 2007;6:31. https://doi.org/10.1186/1476-511X-6-31

62. Moustafa YM, Moustafa RM, Belacy A, Abou-El-Ela SH, Ali FM. Effects of acute exposure to the radiofrequency fields of cellular phones on plasma lipid peroxide and antioxidase activities in human erythrocytes. J Pharm Biomed Anal. 2001;26(4):605-8. https://doi.org/10.1016/s0731-7085(01)00492-7

63. Yamazaki $H$, Matsumoto $K$, Inoue T, Nose T, Murayama $S$, Teshima $T$, et al. Induction of hepatocyte growth factor in the liver, kidney and lung following total body irradiation in rat. Cytokine. 1996;8(12):927-32. https://doi.org/10.1006/ cyto.1996.0124

64. Holten I, Christiansen C. Unchanged parathyroid function following irradiation for malignancies of the head and neck. Cancer. 1984;53(4):874-7. https://doi. org/10.1002/1097-0142(19840215)53:4<874::aidcncr2820530410>3.0.co;2-y

65. Moulder JE, Fish BL, Cohen EP. Impact of angiotensin II type 2 receptor blockade on experimental radiation nephropathy. Radiat Res. 2004;161(3):312-7. https://doi.org/10.1667/rr3129 
66. Wheeler DC, Bernard DB. Lipid abnormalities in the nephrotic syndrome: causes, consequences, and treatment. Am J Kidney Dis. 1994;23(3):331-46. https://doi.org/10.1016/s02726386(12)80994-2

67. Chukwuemeka N, Philippe M, Magdalene N, Onyezuligbo O. Effects of total body irradiation on fatty acid and total lipid content of rats. Pak J Pharm Sci. 2012;25(1):169-73. PMID: 22186326

68. Nwokocha CR, Owu DU, Nwokocha MI, Ufearo CS, Iwuala MO. Comparative study on the efficacy of Allium sativum (garlic) in reducing some heavy metal accumulation in liver of wistar rats. Food Chem Toxicol. 2012;50(2):222-6. https:// doi.org/10.1016/j.fct.2011.11.003

69. Thapa B, Walia A. Liver function tests and their interpretation. Indian J Pediatr. 2007;74(7):663-71. https://doi.org/10.1007/ s12098-007-0118-7
70. Mahady SE, Wong G, Turner RM, Mitchell P, Macaskill P, Craig JC, et al. Elevated liver enzymes and mortality in older individuals: a prospective cohort study. J Clin Gastroenterol. 2017;51(5):43945. https://doi.org/10.1097/MCG.0000000000000622

71 Farid I, Conibear SA. Hepatic function in previously exposed thorium refinery workers as compared to normal controls from the health and nutrition survey. Health Phys. 1983;44(Suppl 1):221-30. https://doi.org/10.1097/00004032-19830600100019

72. Polednak AP. Long-term effects of radium exposure in female dial workers: liver function and liver disease. Environ Res. 1979;18(2):454-65. https://doi.org/10.1016/00139351(79)90121-x

73. Le Cessie $S$, Van Houwelingen JC. Ridge estimators in logistic regression. Appl Stat. 1992;41(1):191201. https:// doi.org/10.2307/2347628 